\title{
OS FUNDAMENTOS DEMOCRÁTICOS DA DECISÃO JUDICIAL E A QUESTÃO DO DIREITO E DA MORAL - UMA VISÃO A PARTIR DO NEOPOSITIVISMO DE HART E A CRÍTICA DE NINO
}

\author{
DEMOCRATIC BASIS OF LEGAL DECISION AND THE ISSUE OF \\ LAW AND MORAL - A VISION FROM HART'S NEW POSITIVISM \\ AND CARLOS SANTIAGO NINO'S CRITIQUE
}

\section{Eneida Desiree Salgado* \\ Emerson Gabardo**}

RESUMO: O texto tem como objetivo descrever parte da argumentação jurídica de dois importantes autores da filosofia do direito do século XX: Herbert Lionel Adolphus Hart e Carlos Santiago Nino. O recorte teórico escolhido foi a questão da decisão judicial, tomando-se como ponto de partida a imprescindibilidade da análise da questão do direito e da moral para o estudo do tema. O assunto é abordado a partir da confrontação de argumentos, tanto dos autores referidos como de outros importantes pensadores que interferiram criticamente no diálogo teórico estudado. Tem-se como objetivo trazer à tona a tradicional discussão realizada em meados do século XX como forma de subsidiar uma adequada reflexão a respeito dos limites e das possibilidades da interpretação do direito e da decisão judicial na contemporaneidade.

PALAVRAS-CHAVE: Herbert L. A. Hart; C. S. Nino; direito e moral; decisão judicial.

* Professora de Direito Constitucional UFPR. Mestre e Doutoranda em Direito do Estado na UFPR.
ABSTRACT: The text has as its main purpose to describe part of the juridical arguments developed by two important Philosophy of Law authors from the 20th century: Herbert Lionel Adolphus Hart and Carlos Santiago Nino. Emphasis is given on the matter of the judicial decision, taking as a starting point the need for the analysis of the matter of Law and of moral. The confrontation between the arguments developed not only by the aforementioned authors but also by other thinkers broaches the subject. The text also aims at putting forth the traditional discussion carried through in the beginning of the 20th century in order to help provide an adequate reflection concerning the limits and the possibilities of interpretation of Law and of the judicial decision nowadays.

KEYWORDS: Herbert L. A. Hart; C. S. Nino; law and moral; judicial decision.

**Professor de Direito Administrativo na UniBrasil. Diretor Geral do Instituto de Direito Romeu Felipe Bacellar. Mestre e Doutorando em Direito do Estado na UFPR. 


\section{ALGO SOBRE HART E NINO}

Uma expressão interessante para definir a variedade de possibilidades epistemológicas compreendidas dentro do chamado “positivismo jurídico" é a utilizada por Jean-Cassien Billier e Aglaé Maryoli: "metamorfoses". ${ }^{1}$ Na realidade, o positivismo jurídico parece ter passado por mudanças substanciais dentro de um mesmo espectro, dependendo da interpretação que lhe confere uma específica escola, um determinado conjunto de pensadores, ou mesmo, a partir da obra de um certo autor. Este é o caso de Herbert Lionel Adolphus Hart, um dos pilares tanto da nova compreensão positivista, típica da metade do século XX, quanto do próprio círculo hermenêutico que lhe sucedeu.

Hart foi advogado sem nunca ter cursado direito. Na realidade, o pensador formou-se em filosofia na Universidade de Oxford em 1930, tendo sido aluno de J. L. Austin. Na época era possível àqueles interessados ao ingresso na advocacia apenas prestar um exame para o exercício da profissão. Foi o que fez Hart, embora por pouco tempo (19301940). Com o advento da Segunda Guerra Mundial, passou a trabalhar para o serviço de inteligência britânica, não retornando mais à advocacia devido à sua aprovação como professor de filosofia em Oxford. ${ }^{2}$

A obra mais importante de Hart, sem dúvida, foi "O Conceito de direito", publicada em 1961 e destinada não à apresentação de

1 BILLIER, Jean-Cassier; MARYOLI, Aglaé. História da Filosofia do direito. Tradução de Maurício de Andrade. Barueri - SP: Manole, 2005, p. 387 e ss.

2 PARANO, Juan Ramón de. Entrevista de H. L. A. Hart. Doxa: Cuadernos de filosofia del derecho, n. 5 (1988), p. 340. uma teoria analítica, mas sim ao estudo da matéria por estudantes da graduação. Segundo o próprio autor, trata-se de um "ensaio de sociologia descritiva" na medida em que não se restringe a propor uma investigação sobre o significado teórico da palavra "direito". Ao contrário, afirma que os conceitos, em geral, são mais bem explicados mediante um estudo sobre os "usos-padrão" de expressões relevantes, ou seja, dependem de um contexto social. ${ }^{3}$

Apesar do sucesso obtido com a publicação, ${ }^{4}$ essa metodologia acabou propiciando uma grande quantidade de críticas, pois a tentativa de aglutinação entre a tradição da "teoria analítica" (Hobbes, Bentham, Austin) e o que autodenominou "sociologia descritiva" não foi muito bem recebida, não só pela pouca expressão epistemológica de seu trabalho, como também pela ausência de uma maior preocupação com a justificação do ponto de vista adotado. ${ }^{5} \mathrm{Na}$ realidade, ao contrário de autores como Ronald Dworkin, que buscam encontrar uma teoria de justificação e interpretação dirigida a uma cultura concreta (o direito anglo-americano), Hart afirmou a intenção de desenvolver uma "teoria geral" (também descritiva) sobre o direito (não

3 HART, Herbert L. A. O conceito de direito. Tradução de A. Ribeiro Mendes. 4.ed., Lisboa: Fundação Calouste Gulbenkian, 2005, p. 01.

4 Segundo Ronald Dworkin o sucesso de Hart decorre de seu "instinto para problemas de princípio e uma lucidez maravilhosa para expô-los". Cf.: DWORKIN, Ronald. Levando os direitos a sério. Tradução de Nelson Boeira. São Paulo: Martins Fontes, 2002, p. 12.

5 ROBLES, Gregório. Hart: algunos puntos críticos. Actas del XVIII Congreso mundial de la Asociación Internacional de Filosofia Jurídica y social. Buenos Aires, 1977, p. 371. 
destinada, portanto, a qualquer ordenamento em concreto). ${ }^{6}$ Esta tentativa de adoção de uma perspectiva ampla acabou propiciando um entendimento mais elastecido do direito que, segundo autores como Gregório Robles, implicaram o desenvolvimento de um "conceito tridimensional": a norma (objeto da ciência analítica); o fato social (objeto da sociologia descritiva); o valor mínimo (objeto do direito natural). ${ }^{7}$

Hart não tem como foco o "direito positivo" e nem mesmo a "ciência jurídica", mas sim o "pensamento jurídico", ${ }^{8}$ a partir de algumas questões recorrentes de caráter fundamental, tais como: a) todos os sistemas jurídicos acabam reproduzindo, em termos substanciais, algumas exigências de caráter moral, ou seja, "o direito e a moral partilham de um vocabulário de direitos e deveres"; b) em geral há um consenso de que o direito é um conjunto de regras, mas a questão fundamental é saber o que são as regras (considerando-se que há uma diferença estrutural entre meros comportamentos convergentes e as regras sociais decorrentes de um dever compartilhado); c) a decisão judicial nunca admite somente um resultado, principalmente nos casos mais importantes, cabendo ao juiz a decisão sobre o que o precedente significa, podendo valer-se de um poder discricionário subjetivo, se necessário; d) o direito não é apenas baseado em ameaças

6 HART, Herbert L. A. O conceito de direito. Op. cit., p. 300.

7 ROBLES, Gregório. Hart: algunos puntos críticos. Op. cit., p. 372.

8 ROBLES, Gregório. Hart: algunos puntos críticos. Op. cit., p. 373. ou comandos, como propõe o positivismo clássico de Austin. ${ }^{9}$

Contemporâneo de Hart, Carlos Santiago Nino nasceu na Argentina em 1943, tendo graduado-se em direito na Universidade de Buenos Aires e realizado seu doutorado em Oxford, na Inglaterra. Sua notoriedade lhe rendeu convites para ser professor visitante na Universidade de Yale (EUA) e na Universidade Pompeu Fabra (Espanha), entre outras instituições. Durante o governo de Raúl Alfonsín foi assessor presidencial e coordenador do Consejo para la consolidación de la democracia, que buscava reformar o Estado argentino recém-democratizado no início dos anos 80. Nino foi designado membro da Comissão de Reforma do Código Penal, além de ter sido o responsável pela criação do importante Centro de Estudos Constitucionais. Acabou falecendo em 1993, vitimado por uma crise de asma em La Paz, onde trabalhava na reforma da Constituição boliviana.

Assim como ocorreu com Hart, ${ }^{10}$ os primeiros escritos de Nino se concentraram na teoria do direito e da moral, no conceito de sistema jurídico, na interpretação legal, no debate entre juspositivismo e jusnaturalismo e no conceito de validade das normas. $\mathrm{Ou}$, como ele mesmo afirma, centraram-se na "metodologia da ciência jurídica e da decisão judicial". Na teoria do direito afastou a análise dogmática de inspiração no

9 HART, Herbert L. A. O conceito de direito. Op. cit., p. 10-21.

${ }^{10}$ Para o conhecimento de alguns dos primeiros ensaios de Hart a respeito das temáticas ora tratadas ver a coletânea organizada por Genaro Carrió: HART, Herbert. L. A. Derecho y moral: contribuciones a su análisis. Tradución de Genaro Carrió. Buenos Aires: Depalma, 1962. 
pensamento alemão e propôs um modelo baseado na adoção explícita de princípios de justiça e moralidade social. Suas investigações filosóficas sempre se voltaram para problemas práticos, como o concurso no direito penal, a legítima defesa e o aborto, em uma relação teoria/aplicação bastante intensa. Característica esta que também o aproxima de Hart, que foi um ativista político preocupado com as questões reais de seu tempo. ${ }^{11}$

Particularmente para o presente estudo, centrado na questão da decisão judicial e os limites da relação entre o direito e a moral, interessa a tese de Nino de que "a motivação justificatória de soluções jurídicas requer necessariamente premissas valorativas, o que tem conseqüências sumamente relevantes para a ciência jurídica e para a administração da justiça." ${ }^{12}$ Desse modo, torna-se possível ser estabelecida uma ponte entre seu pensamento crítico e as proposições inovadoras de Hart, contidas de forma sistematizada em "O Conceito do direito" ou em outros trabalhos como "Derecho y Moral: contribuciones a su análisis". Para o estudo do pensamento de Nino sobre a decisão

11 Veja-se, por exemplo, as polêmicas posições de Hart sobre a descriminalização das práticas homossexuais e da prostituição (particularmente decorrentes dos trabalhos da Comissão Wolfenden, em 1957). Sobre o assunto e a forte controvérsia com Lord Devlin ver: MALEM, Jorge. De la imposición de la moral por el derecho: la disputa Devlin-Hart. Revista Isonomía. n. 04 (1996). Ver também os comentários de Ronald Dworkin em: DWORKIN, Ronald. Levando os direitos a sério. Op. cit., p. 375 e ss.

12 Apresentação de si mesmo, de sua trajetória filosófica e das principais questões da teoria do direito que Carlos Santiago Nino faz no primeiro número da revista Doxa: Cuadernos de Filosofía del Derecho. Universidad de Alicante, 1984, p. 175-177. judicial e sobre posição de Hart será utilizada principalmente sua obra "Derecho, Moral y Política. Una revisión de la teoría general del Derecho".

\section{A RELAÇÃO ENTRE DIREITO E MORAL}

O neopositivismo hartiano propõe de forma inovadora que o ser e o dever ser estão unidos e são inseparáveis, ainda que grandes positivistas como Bentham e Austin não admitam esta realidade, por insistirem que o direito é, necessariamente, o "direito que deve ser". ${ }^{13}$ Hart, na realidade, ao firmar sua posição não recusa a distinção entre a esfera do ser e a do dever ser. Contudo, relativiza o exagero do positivismo clássico (que simplesmente negou a esfera do ser) mediante a proposição da íntima conexão entre as duas esferas.

Nino não se contenta com este suave avanço, asseverando que "o argumento de Hart e de tantos outros positivistas de que há que distinguir o direito que 'é' do direito que 'deve ser' pressupõe um conceito descritivo de direito como um conjunto de normas que são de fato reconhecidas". Mas, segundo o autor, caso fosse adotado "um conceito valorativo de direito, como um conjunto de normas que devem ser reconhecidas, se poderia estabelecer a mesma distinção mas empregando conceitos diferentes: haveria de distinguir entre 'o que é considerado' direito e o que 'é direito', correspondendo cada termo deste segundo par aos termos do primeiro par na mesma ordem."14

${ }^{13}$ HART, Herbert L. A. Derecho y moral: contribuciones a su análisis. Op. cit., p. 3.

${ }^{14}$ NINO, Carlos Santiago. Derecho, moral y política. Una revisión de la teoría general del Derecho. Barcelona: Ariel, 1994, p. 33. 
Hart, na defesa de sua posição de positivista moderado, encampa a idéia de que a identificação de um conceito de direito inserido na realidade conjuntural exige o reconhecimento de que na aplicação das regras sempre haverá uma dualidade entre um "núcleo de certeza" e uma "penumbra de dúvida”. Esta imprecisão implica a existência de uma textura aberta, típica do sistema jurídico e do conceito de direito que o autor procura descrever. ${ }^{15}$

Santiago Nino, contudo, vai além e questiona a própria necessidade de um "conceito de direito", afirmando que o debate entre as diversas escolas de pensamento parte de diferentes concepções do que seja direito defendidas como se fossem as verdadeiras e únicas aceitáveis. $\mathrm{O}$ autor acentua que a palavra "direito" tem um "significado emotivo favorável. Nomear com esta palavra uma ordem social implica condecorar-lhe com um rótulo honorífico e reunir ao seu redor as atitudes de adesão das pessoas". ${ }^{16}$ Essa conotação emotiva prejudica o

${ }^{15}$ HART, Herbert L. A. O conceito de direito. Op. cit., p. 129. Artur Stamford da Silva, Murilo Otávio Lubambo de Melo e Romero Barreto Barbosa, em bemhumorado artigo, afirmam que Hart critica o formalismo, relacionado à hermenêutica tradicional - que pretende retirar da lei uma única decisão correta por um processo estritamente intelectual - e também o ceticismo, espécie de voluntarismo amorfo que vê no juiz o criador do direito, afirmando que "suas idéias são uma espécie de evolução de dialética resultante do confronto entre essas duas correntes extremadas". SILVA, Artur Stamford et alli. Construção judicial do direito. Desde Kelsen e Hart. Ainda somos os mesmos... e vivemos. Revista de Informação Legislativa, Brasília, n. 165, p. 205-218, jan/ mar 2005 .

${ }^{16}$ NINO, Carlos Santiago. Introducción al análisis del derecho. Buenos Aires: Editorial Astrea de Alfredo y Ricardo Depalma, 1998, p. 16. significado cognoscitivo da palavra, porque provoca ora sua extensão, ora sua restrição.

Ante a vagueza da palavra "direito", alguns juristas essencialistas buscam incessantemente construir um liame entre os diversos fenômenos jurídicos para permitir sua compreensão intrínseca. E, a partir do pressuposto da existência ou não de uma relação entre direito (cada qual com seu próprio conceito) e moral, coloca-se a disputa entre jusnaturalismo e juspositivismo e suas derivações.

Para Nino os conceitos são criações convencionais (que não refletem a essência do objeto) estabelecidos por exigência de entendimento e de comunicação. Nesta posição convencionalista, admite a existência de uma pluralidade de conceitos de direito, adequados a distintas necessidades discursivas. ${ }^{17}$ Aduz, ainda, que cada conceito de direito admitido leva a um conjunto distinto de razões admitidas para a justificação das decisões jurídicas. ${ }^{18}$

Levando em conta apenas os standards efetivamente reconhecidos pelos órgãos primários, responsáveis pela aplicação do

17 NINO, Carlos Santiago. Derecho, moral y política. Una revisión de la teoría general del Derecho. Op. cit., p. 32. Na página seguinte, Nino se refere diretamente ao título da obra de Hart e à armadilha da pretensão de um conceito exclusivo e excludente de direito.

18 "Por exemplo, os jusfilósofos realistas, como Alf Ross, adotam um conceito descritivo realista de direito, considerando como tal o "conjunto de standards que são ou serão provavelmente e de fato reconhecidos - ou seja, empregados ou empregáveis na exposição de razões justificatórias de suas decisões - por parte de quem tenha capacidade efetiva de mobilizar em casos concretos, através de tais decisões, o aparato que quase monopoliza a coação em uma sociedade". Cf.: NINO, Carlos Santiago. Derecho, moral y política. Una revisión de la teoría general del Derecho. Op. cit., p. 36. 
direito, pelo fato de terem sido prescritos por uma certa autoridade ou fonte e excluindo outras razões que podem participar da construção da decisão judicial (como os precedentes, os costumes e os princípios) o conceito descritivo institucional de direito pode ser ainda mais restrito (quando exclui do conceito de direito todos os standards que os órgãos primários não estejam obrigados a aplicar). Aqui se localizam, para Nino, Hart e Joseph Raz e é daqui que partem as críticas de Dworkin contra o positivismo. ${ }^{19}$

Os conceitos normativos de direito consideram o conjunto de standards que devem ser reconhecidos na aplicação do direito. O problema está na definição do que torna obrigatório o comando que torna os demais comandos obrigatórios. De acordo com Nino, para que não seja auto-referente este primeiro comando está além do dever, está além do círculo compreendido como direito. Aqui cabe uma crítica à teoria de Kelsen, cujo entendimento Nino denomina de conceito "normativo hipotético de direito". ${ }^{20}$

Hart possui uma compreensão a respeito do direito que não permite tal relativismo conceitual (ainda que aceite a influência do relativismo fático). Segundo o autor, em qualquer grande grupo, as regras gerais, os padrões e os princípios devem ser o mais importante mecanismo de controle da sociedade, e não as diretivas particulares dadas separadamente a cada um. Sua pretensão de universalidade, característica da tradição analítica, busca um conceito de direito

${ }^{19}$ NINO, Carlos Santiago. Derecho, moral y política. Op. cit., p. 37.

${ }^{20}$ NINO, Carlos Santiago. Derecho, moral y política. Op. cit., p. 37-38. aplicável em diferentes sistemas. Para tanto, o autor busca características que se façam presentes neste modelo a ser construído. E uma das mais importantes características é justamente a sua "textura aberta", que decorre, portanto, da inter-relação social, consistindo em um aspecto da própria linguagem humana, além do que, retrata um certo "preço a pagar" pela adoção de classificações gerais. ${ }^{21}$

Ademais, a própria inabarcabilidade das situações de fato, aliada a uma "relativa indeterminação" das ações humanas também impõe um caráter faticamente aberto ao sistema. ${ }^{22}$ De acordo com Jean-Cassien Billier e Aglaé Maryoli, a consequiência desta formulação é que a aplicação das regras irá depender da sua finalidade. Existem casos em que não se apresenta qualquer dúvida; já há outros em que se apresentam dúvidas. O núcleo de certeza da regra depende, portanto, de dois fatores essenciais: a) a formulação lingüística (seja ela descritiva, seja ela de avaliação); e b) o contexto de aplicação (organização do processo, fatos, provas). Ou seja, "a mesma regra jurídica que em certo caso é clara, precisa e não traz nenhuma dificuldade de interpretação, pode não ser assim em um caso diferente". ${ }^{23}$

Neste ponto, Nino concorda com Hart. As indeterminações semânticas exigem uma determinação por parte do intérprete que demanda valorações. É a textura aberta das

${ }^{21}$ HART, Herbert L. A. O conceito de direito. Op. cit., p. 137.

${ }^{22}$ HART, Herbert L. A. O conceito de direito. Op. cit., p. 141.

${ }^{23}$ BILLIER, Jean-Cassier; MARYOLI, Aglaé. História da Filosofia do direito. Op. cit., p. 403. 
normas jurídicas derivada da linguagem reconhecida por Hart que dá ao intérprete um espaço de discricionariedade em face da vagueza (por gradiente, combinatória, por textura aberta) e da ambigüidade. A aplicação da norma a um caso concreto exige a superação das indeterminações semânticas, sintáticas e pragmáticas, em um momento essencial e inafastavelmente valorativo. ${ }^{24}$ Ainda, na interpretação, há eventualmente a necessidade de preencher uma lacuna lógica (quando o sistema jurídico não oferece uma solução normativa para determinado caso), afastar uma contradição lógica ou uma redundância; exige-se também a superação das indeterminações lógicas. Para Nino, ainda que existam regras para afastar essas indeterminações, há, sempre, um espaço que somente pode ser preenchido com opções de índole moral, muitas vezes declaradas sob a alegação de que aquela escolhida é a solução mais justa. Finalmente há interferência de opções valorativas quando se dá a subsunção da norma ao caso concreto, com uma revisão das opções valorativas já realizadas ${ }^{25}$. Ou seja, em todos os passos da aplicação do direito estão presentes, inafastavelmente, considerações não-jurídicas, de índole moral. A negação de tais valorações, mascarando-as em argumentos pretensamente puramente jurídicos, impede a avaliação da decisão pela não declaração dos reais motivos que a fundamentam.

O positivismo jurídico clássico afirma poder determinar uma solução correta -

${ }^{24}$ NINO, Carlos Santiago. Derecho, moral y política. Op. cit., p. 87-95.

25 NINO, Carlos Santiago. Derecho, moral y política. Op. cit., p. 95-100. unívoca, consistente, precisa e isenta de considerações morais - para cada caso, com neutralidade valorativa e com uma lógica irretocável. E, desta forma, sustenta ser o ordenamento jurídico completo, coerente e razoável, onde o juiz, ainda que lhe sobre algum espaço de decisão, decidirá nos limites no conjunto de opções da própria ordem jurídica. Nada mais inatingível por críticas à ordem posta e à atuação plena do Poder Judiciário na realização do direito e na proteção do sistema. ${ }^{26}$

Santiago Nino, vai além de Hart e defende uma conexão direta entre direito e moral. $\mathrm{O}$ autor enfrenta, portanto, os paradoxos de ser considerada essa conexão, que poderia levar, inclusive, à irrelevância do direito para a solução de casos concretos, afirmando que, por vezes, uma norma jurídica afasta uma indeterminação moral. ${ }^{27}$

Para Nino o direito é uma prática política, tanto em sua elaboração quanto em sua aplicação. A estrutura da motivação prática tem que ter em conta que as ações ou decisões jurídicas são parte de um processo duradouro de interação coletiva. Há uma racionalidade específica quando se participa em uma obra coletiva, com uma ação que se soma à obra sem que o autor tenha o controle sobre toda a obra. ${ }^{28}$

${ }^{26}$ NINO, Carlos Santiago. Derecho, moral y política. Op. cit., p. 101-102.

${ }^{27}$ NINO, Carlos Santiago. Derecho, moral y política. Op. cit., p. 130-131.

28 "O que resulta afetado, e se modifica quando atuamos coletivamente em vez de individualmente, não é a validade dos princípios valorativos últimos. As ações coletivas requerem diferentes critérios de racionalidade na eleição de princípios ou modelos valorativos, posto que, como nossa agregação a uma obra coletiva é 
Mais restritivo, propõe Hart que é fator característico de um sistema com textura aberta e, ainda, deve ser típico de um "bom sistema jurídico", a sua conformação com a justiça e com a moral. ${ }^{29}$ Todavia, não há uma correlação necessária entre direito e moral. Diferentemente do direito, as características fundamentais da moral são: a) importância (ou relevância social); b) imunidade à alteração deliberada (a moral é algo que “existe para ser reconhecido e não feito por uma ação humana intencional"); c) caráter voluntário (os delitos morais dependem da vontade consciente do agente); d) a existência de uma forma de pressão social específica. ${ }^{30}$

Quanto à justiça, trata-se da "mais jurídica das virtudes" e a "mais pública delas", ${ }^{31} \mathrm{em}$ razão do que implica a existência de certos deveres que exigem o sacrifício de interesses privados, o que é uma situação essencial à própria sobrevivência de qualquer sociedade. ${ }^{32}$ Mas, na realidade, os "princípios de justiça" nada mais são do que um segmento da própria

limitada e não controlamos o produto final, o racional pode ser eleger, não o modelo ou princípio mais defensável, senão outros como méritos menores. Este tipo de racionalidade, constrita na obra coletiva pelas eleições dos demais, poderia ser denominada de 'o segundo melhor', considerando que, muitas vezes, nos leva a um afastamento progressivo do modelo ótimo, em atenção a seus efeitos sobre a obra global". Cf.: NINO, Carlos Santiago. Derecho, moral y política. Op. cit., p. $136-137$.

${ }^{29}$ HART, Herbert L. A. O conceito de direito. Op. cit., p. 221.

${ }^{30}$ HART, Herbert. L. A. O conceito de direito. Op. cit., p. 190 e ss.

${ }^{31}$ HART, Herbert. L. A. O conceito de direito. Op. cit., p. 182.

${ }^{32}$ HART, Herbert. L. A. O conceito de direito. Op. cit., p. 186. moral em que se busca a realização de uma situação fática eqüitativa em que se deve tratar "da mesma maneira casos semelhantes e diferentemente os casos diferentes". ${ }^{33}$

Por outro lado, Nino apresenta um conceito misto de direito que, segundo propõe, se coaduna com a concepção interpretativa de direito de Dworkin e que não aceita os termos da relação entre direito e moral presentes em Hart. ${ }^{34}$ Essa pluralidade de conceitos aceitáveis de direito defendida por Nino impede que se estabeleça como verdadeira uma determinada relação conceitual entre direito e moral.

Para o positivismo jurídico clássico, tradicionalmente opositor do jusnaturalismo, não é necessário, de forma alguma, que as leis satisfaçam exigências da moral para que sejam válidas (embora freqüentemente façam isso). ${ }^{35}$ Todavia, a aplicação do direito requer decisões humanas cuja lógica ou racionalidade implica uma decisão sobre o que o direito “deve ser”; e isso já é um juízo moral. Por este motivo não é possível negar que há uma ligação necessária entre o direito e a moral. Tanto o utilitarismo de Jeremy Bentham quanto o positivismo de John Austin erraram, segundo Hart, porque se desligaram da

${ }^{33}$ HART, Herbert L. A. O conceito de direito. Op. cit., p. 173.

${ }^{34}$ Segundo Nino "o direito está formado por aqueles standards reconhecidos efetivamente em suas decisões por quem tem acesso ao aparato coativo para fazer cumprir tais decisões e aqueles standards que devem ser reconhecidos por eles como a melhor justificação do reconhecimento do primeiro tipo de Standard." NINO, Carlos Santiago. Derecho, moral y política. Op. cit., p. 39.

${ }^{35}$ HART, Herbert L. A. O conceito de direito. Op. cit., p. 202. 
aplicação do direito, preocupando-se em demasia com o formalismo. ${ }^{36}$

Hart ressalta que esta dicotomização não traduz a relação verdadeiramente existente entre direito e moral. Aliás, o seu próprio entendimento a respeito do que seja direito passa pela confirmação social de uma necessária conexão entre as instâncias. Afirma o autor que "sem a cooperação voluntária deles [um número relevante de pessoas] assim criando autoridade, o poder coercitivo do direito e do governo não pode estabelecer-se". ${ }^{37}$ Ademais, a prática verificável em sistemas como os EUA e a Inglaterra denota que o critério último de validade jurídica incorpora explicitamente "princípios de justiça ou valores morais substantivos". ${ }^{38}$ Nesse sentido, também propõe Dworkin que a leitura moral não é algo novo, pois ela está refletida nas interpretações que se utilizam de uma forma coerente de hermenêutica da Constituição. Tal situação é exemplificada com a facilidade com que é possível distinguir juristas liberais e conservadores. Cada qual se diferencia pela sua peculiar visão moral da Constituição, que vai influenciar na interpretação dos princípios. ${ }^{39}$

${ }^{36}$ Embora lembra o autor que Austin não entendia o direito como um sistema fechado, pois a própria natureza da linguagem é aberta. Cf.: HART, Herbert. L. A. Derecho y moral: contribuciones a sua análisis. Op. cit., p. 28.

${ }^{37}$ HART, Herbert L. A. O conceito de direito. Op. cit., p. 217.

${ }^{38}$ HART, Herbert L. A. O conceito de direito. Op. cit., p. 220.

39 DWORKIN, Ronald. La lectura moral y la premisa mayoritarista. In: $\mathrm{KOH}$, Harold Hongju e SLYE, Ronald (Comp.). Democracia deliberativa y derechos humanos. Barcelona: Gedisa, 2004, p. 152. O argumento já havia
Entretanto, embora tenham opiniões coincidentes quanto à existência de alguma conexão entre direito e moral, as concepções de Hart e Dworkin diferem radicalmente na forma e termos em que se estabelece esta conexão. Hart sustenta que "não há conexões conceituais necessárias entre o conteúdo do direito e o da moral", ainda que o direito possa ter incorporado critérios morais para sua identificação. Desse modo, entende que podem "ter validade, enquanto regras ou princípios jurídicos, disposições moralmente iníquas". ${ }^{40}$ Dworkin discorda desta possibilidade e, ademais, chega a afirmar que, apesar da evolução propiciada pela teoria de Hart (sobre a de Austin), ${ }^{41}$ o autor nada mais é do que "o mais claro exemplo da teoria positivista". ${ }^{42}$

Isso ocorre, pois Hart é direto ao afirmar a necessidade de uma "concepção moral

sido inicialmente desenvolvido em: DWORKIN, Ronald. Levando os direitos a sério. Op. cit. e DWORKIN, Ronald. $O$ império do direito. Tradução de Jefferson Luiz Camargo. São Paulo: Martins Fontes, 1999.

${ }^{40}$ HART, Herbert. L. A. O conceito de direito. Op. cit., p. 331.

41 "Hart resgata os princípios fundamentais do positivismo dos erros de Austin. Hart concorda com Austin que as regras jurídicas válidas podem ser criadas através de atos de autoridades e instituições públicas. Contudo, Austin pensava que a autoridade dessas instituições encontrava-se tão-somente no seu monopólio do poder. Hart localizava a autoridade dessas instituições no plano dos padrões constitucionais a partir dos quais elas operam, padrões constitucionais esses previamente aceitos pela comunidade que é por eles governada, na forma de uma regra de reconhecimento fundamental. Esse plano legitima as decisões do governo e lhes confere a forma e o caráter de obrigação que faltavam às ordens cruas do soberano de Austin." Cf.: DWORKIN, Ronald. Levando os direitos a sério. Op. cit. p. 34.

${ }^{42}$ DWORKIN, Ronald. Levando os direitos a sério. Op. cit. p. 74. 
neutra". Ou seja, discorda de Dworkin (e Nino) principalmente por conta da aceitação (por estes autores) de uma moralidade que não está expressa na Constituição, nem na legislação, nem nos precedentes, mas pode ser acatada como efetivos princípios jurídicos. Sendo assim, Dworkin aceita a equivalência entre princípios implícitos e explícitos propiciando uma interferência (indevida) da moral no direito. ${ }^{43}$ Hart recusa esta possibilidade, ao tempo em que também nega a interpretação (errada) que Dworkin faz de sua teoria, quando a denomina de um mero "positivismo factual", pois, para o autor, os critérios últimos de validade de uma ordem jurídica podem incorporar explicitamente "princípios de justiça" ou valores morais substantivos (sem que isso implique uma confusão entre direito e moral). Desse modo, prefere intitular-se como um "positivista moderado". ${ }^{44}$

O positivismo tradicional, bem representado por John Austin, afirma que a existência do direito deve corresponder à presença de um soberano político (que estabelece um comando a ser obedecido habitualmente).$^{45}$ Hart critica esta percepção do fenômeno jurídico explicando que há uma variedade de imperativos na vida real. Um assaltante, por exemplo, não emite uma simples "ordem", decorrente do respeito por uma autoridade (em que se presume

${ }^{43}$ PARANO, Juan Ramón de. Entrevista de H. L. A. Hart. Op. cit., p. 346.

${ }^{44}$ HART, Herbert. L. A. O conceito de direito. Op. cit., p. 309.

45 BILLIER, Jean-Cassier; MARYOLI, Aglaé. História da Filosofia do direito. Op. cit., p. 397. hierarquia); ele emite ordens baseadas em ameaças, visando à obediência. $\mathrm{O}$ direito também possui regras gerais e, sem dúvida, há probabilidade de sua execução mediante ameaças. Todavia, seu fundamento ultrapassa a questão da ameaça, pois há um hábito geral de obediência que produz supremacia dentro de um território e independência em face de outros sistemas. ${ }^{46}$ Nesta perspectiva, o povo não é um soberano livre de limitação jurídica, havendo um rompimento com as teorias clássicas da soberania e da democracia, devido à regulação decorrente do sistema jurídico. ${ }^{47}$ Desse modo, este "hábito geral", baseado em regras, não se confunde com o "costume", pois este não é direito. O costume só é direito se faz parte de uma categoria de costumes que é "reconhecida" pelo direito (reconhecimento jurídico - com a participação do soberano). O "súdito" presta obediência habitual e esta relação é tão essencial ao direito como "a coluna vertebral o é no homem": hábito de obediência, continuidade da autoridade de criação, persistência das leis para além do desaparecimento do autor - estas são características fundamentais do direito. ${ }^{48}$

Essa relação permite a identificação, na esfera social, de regras gerais que possuem dois aspectos fundamentais: o aspecto interno e o aspecto externo. O aspecto interno diferencia o "bom" do "mal"; implica uma opinião consolidada sobre a correção da regra

${ }^{46}$ HART, Herbert. L. A. O conceito de direito. Op. cit., p. 26-29.

${ }^{47}$ HART, Herbert. L. A. O conceito de direito. Op. cit., p. 87.

${ }^{48}$ HART, Herbert. L. A. O conceito de direito. Op. cit., p. 59. 
e que gera a crítica ao desvio. ${ }^{49}$ Conforme descreve Hart, "para que uma regra social exista, alguns membros, pelo menos, devem ver no comportamento em questão um padrão geral a ser observado pelo grupo como um todo". Já o aspecto externo reporta-se à existência fática de um hábito social regular e uniforme de qualquer um. ${ }^{50}$

Santiago Nino relaciona os conceitos descritivo e normativo do direito com a posição do observador externo e a dos participantes da prática jurídica e com a distinção de Hart entre o ponto de vista externo e o ponto de vista interno em relação ao direito. Ressalta, no entanto, que a visão de Hart é sempre dentro do seu conceito de direito, puramente descritivo. ${ }^{51} \mathrm{~A}$ análise desde esses dois pontos de vista não é exclusiva do direito, mas alcança qualquer outra configuração da práxis humana, como por exemplo a moral positiva. Tomada esta como uma prática social, é possível, desde o ponto de vista externo, compreendê-la como um conjunto de condutas e atitudes tomadas desde a adesão a juízos normativos a partir de sua presumida validade intrínseca e que permite desvalorar condutas distoantes; e, de um ponto de vista interno, considerá-la como um conjunto de princípios válidos. ${ }^{52}$

49 Segundo Billier e Maryoli o aspecto interno das regras implica uma atitude crítica e reflexiva em razão do que os comportamentos desviantes são reprovados pelo grupo social. Cf.: BILLIER, Jean-Cassier; MARYOLI, Aglaé. História da Filosofia do direito. Op. cit., p. 398.

${ }^{50}$ HART, Herbert. L. A. O conceito de direito. Op. cit., p. 65 .

51 NINO, Carlos Santiago. Derecho, moral y política. Op. cit., p. 43-45.

52 NINO, Carlos Santiago. Derecho, moral y política. Op. cit., p. 45.
Tanto com relação ao direito como em relação à moral, há uma primazia lógica do ponto de vista interno sobre o externo ${ }^{53}$. Não é possível compreender a moral positiva de uma sociedade sem passar pelo juízo que faz o sujeito quando toma como válido determinado princípio. Assim, para Nino, também se passa com o direito. Sua tese, como já apontado, é que a perspectiva interna relaciona-se com o direito em seu viés normativo e "está indissoluvelmente ligada à perspectiva interna da moral e, em especial, à perspectiva interna da prática discursiva que a modernidade acoplou à moral positiva". E afirma: "Se isso é assim, a perspectiva externa do direito como prática social se distorce se não relaciona explicativamente essa prática social com a prática social do discurso moral". ${ }^{54}$

A partir da relação entre as perspectivas interna e externa, Hart distingue com adequação duas situações aparentemente idênticas: "ter a obrigação de fazer", que independe de fatos e motivos para agir e "ser obrigado a fazer", em que pode ser observada a existência de crenças e motivos pelos quais há uma ação. Assim diferencia-se a idéia de "dever" da idéia de "obrigação". As regras primárias são relativas diretamente às obrigações, propiciando incerteza e uma certa ineficácia da pressão social difusa. As regras secundárias têm a função de corrigir a função das regras primárias, conferindo a elas sistematicidade e dinamicidade a partir de "regras de reconhecimento", "regras de

${ }^{53}$ NINO, Carlos Santiago. Derecho, moral y política. Op. cit., p. 47.

${ }^{54}$ NINO, Carlos Santiago. Derecho, moral y política. Op. cit., p. 50. 
alteração" e "regras de julgamento". Assim as regras secundárias remediam a ineficácia das primárias de três formas: a) estabelecendo um critério de identificação; b) definindo o processo de inclusão de regras primárias no sistema; e c) conferindo poder aos sujeitos para dizer, com autoridade, se determinada regra foi violada em uma situação concreta. ${ }^{55}$

Hart abandona a noção fundamental de Austin de que "os fundamentos de um sistema jurídico consistem num hábito de obediência a um soberano juridicamente ilimitado", afirmando que o adequado fundamento do direito está na existência da "regra última de reconhecimento". ${ }^{56}$ Esta regra de caráter particular possui uma íntima ligação com a validade jurídica. Trata-se de um "critério supremo" que na modernidade implica uma combinação de critérios (até porque, como ocorre no direito inglês, várias são as fontes, como a lei, as decisões e o costume). ${ }^{57}$ A característica fundamental que a diferencia de outras regras é porque ela somente existe como uma efetiva "prática" (dos tribunais, dos funcionários, dos particulares) ao identificarem o direito por intermédio de certos critérios. Desse modo, a "sua existência é uma questão de fato". 58

Robles afirma que esta concepção de Hart possui uma série de contradições e ambigüidades. A regra de reconhecimento

${ }^{55}$ HART, Herbert. L. A. O conceito de direito. Op. cit., p. 104-106.

${ }^{56}$ HART, Herbert. L. A. O conceito de direito. Op. cit., p. 122.

${ }^{57}$ HART, Herbert. L. A. O conceito de direito. Op. cit., p. 112.

${ }^{58}$ HART, Herbert. L. A. O conceito de direito. Op. cit., p. 121. nada mais faria do que afirmar que o hábito de obediência é o fator determinante de identificação das regras, na medida em que não faz parte do direito positivo, mas sim decorre da sua aceitação generalizada. $\mathrm{O}$ autor afirma que Hart seria mais bem sucedido se ao invés de ter criado a "misteriosa" regra de reconhecimento, tivesse dito simplesmente que a identificação das regras de um sistema ocorre mediante a observação de sua aceitação prática.$^{59}$ Ricardo A. Guibourg segue a linha crítica asseverando que a regra de reconhecimento nada mais é do que uma "versão soft" da norma fundamental de Kelsen, ${ }^{60}$ o que é contestado por Hart ao afirmar que a regra de reconhecimento, embora semelhante, diferencia-se da "norma fundamental" de Kelsen porque: a) é um dado empírico, de fato (a norma fundamental é uma suposição); b) admite como fonte e critério de validade jurídica os princípios e valores morais (já a norma fundamental não aceita que uma regra jurídica válida seja afastada por um princípio moral conflitante). ${ }^{61}$

Para Nino, o conceito de validade jurídica é a ponte entre o discurso jurídico justificatório e o discurso moral. A validade não se resume à eficácia ou ao pertencimento a um sistema jurídico (como pressupõe um conceito descritivo) ou à justificabilidade ou à força obrigatória (como em uma concepção

59 ROBLES, Gregório. Hart: algunos puntos críticos. Op. cit., p. 393-398.

${ }^{60}$ GUIBOURG, Ricardo A. Hart, Bulygin y Ruiz Manero: tres enfoques para un modelo. Doxa: Cuadernos de Filosofia del derecho, n. 14, 1993, p. 429.

${ }^{61}$ HART, Herbert. L. A. O conceito de direito. Op. cit., p. 274. 
normativa). A validade exige considerações para além da esfera jurídica. ${ }^{62}$ Desta forma é que devem ser analisadas suas críticas ao positivismo kelseniano e ao neopositivismo de Hart. Tanto a norma fundamental hipotética quanto a regra de reconhecimento último (sejam elas identificáveis ou não) são inconcebíveis no interior de uma lógica puramente jurídica - levando em consideração o direito como conceituado pelo positivismo. A fundamentação última de ambas as teorias contradiz seu desenvolvimento, pois remete a uma aceitação no âmbito moral. ${ }^{63}$

Nino se debruça sobre a teoria de Hart e menciona o "paradoxo de Ross" em relação às alterações da regra de reconhecimento em função do que ela mesma dispõe. Alf Ross aponta a necessidade de ser assumida uma auto-referência inexplicável da regra de reconhecimento e também sua perpetuidade como fundamento de validade de outras regras, ainda quando já não exista mais por força de sua modificação substancial. ${ }^{64}$

A norma que determina a observância contínua da Constituição - ainda quando for modificada, desde que de forma regular - é logicamente anterior à Constituição, ápice do ordenamento jurídico positivo. Para Kelsen,

${ }^{62}$ NINO, Carlos Santiago. Derecho, moral y política. Op. cit., p. 72.

${ }^{63}$ E mesmo no âmbito da fundamentação moral Nino renuncia a uma fundamentação última e afirma que somente é possível um discurso coletivo moral localizado no tempo e no espaço. Para uma análise mais do que qualificada de sua teoria ver: ALEXY, Robert. La fundamentación de los derechos humanos en Carlos $S$. Nino. Doxa: Cuadernos de Filosofía del Derecho. Universidad de Alicante. n. 26, 2003, p. 173-201.

${ }^{64}$ NINO, Carlos Santiago. Derecho, moral y política. Op. cit., p. 73. essa norma básica é uma norma hipotética (ficcional, segundo sua obra tardia) e para Ross a obediência à Constituição deriva de uma ideologia pressuposta. Ambos os fundamentos estão fora do âmbito jurídico, para além do campo normativo. São princípios extrajurídicos, já no campo da moral. ${ }^{65}$

Embora Kelsen mantenha a terminologia normativa, denominando "norma" a razão de obediência do sistema jurídico, a observância desta "norma" não deriva de outra norma ou de sua formulação por uma autoridade competente. ${ }^{66}$ Ainda que os jusfilósofos positivistas neguem há, no fundamento da ordem jurídica, um conceito de validade como força obrigatória moral.

Nino sustenta que o discurso jurídico não é isolado, mas tampouco é uma parcela do discurso moral. O discurso moral, como estrutural da modernidade, transpassa todo discurso justificatório, exceto quando ele mesmo exclui sua aplicação, "seja porque se mova em uma dimensão diferente, ou porque defina uma área de indiferença, ou porque seja aplicável algum princípio defensível no discurso moral e que permita a justificação

${ }^{65}$ NINO, Carlos Santiago. Derecho, moral y política. Op. cit., p. 74-75.

66 "A ordem jurídica, especialmente a ordem jurídica cuja personificação é o Estado, é, portanto, não um sistema de normas coordenadas entre sim que se acham, por assim dizer, lado a lado, no mesmo nível, mas uma hierarquia de diferentes níveis de normas. A unidade dessas normas é constituída pelo fato de que a criação de uma norma - a inferior - é determinada por outra - a superior - cuja criação é determinada por outra norma ainda mais superior, e de que esse regressus é finalizado por uma norma fundamental, a mais superior, que, sendo o fundamento supremo de validade da ordem jurídica inteira, constitui a sua unidade". KELSEN, Hans. Teoria Geral do direito e do Estado. Tradução de Luís Carlos Borges. São Paulo: Martins Fontes, 2000. p. 181. 
própria de algum subdiscurso." ${ }^{67}$ Esse não é o caso do direito. Razões relacionadas a interesses pessoais ou a um cálculo econômico de eficiência são insuficientes para preencher a necessidade de justificação das decisões jurídicas. ${ }^{68}$ Conclusão esta que afasta totalmente Nino (e neste ponto também Hart) de qualquer abordagem analítico-econômica de justificação do direito (como em Richard Posner, por exemplo). ${ }^{69}$

Nino destaca que mesmo a fundamentação democrática, que relaciona a força obrigatória das normas jurídicas ao consentimento dos interessados - mais alegórico do que factual implica em um princípio moral que convalida o consentimento. Afinal, tomando o direito para além de uma conceituação puramente descritiva, "não existem razões jurídicas que possam justificar ações e decisões com independência de sua derivação de razões morais". ${ }^{70}$ Quando o discurso jurídico se limita a justificar as decisões com base em normas jurídicas, pressupõe uma justificação extrajurídica que reconhece como válido o conjunto de normas jurídicas.

${ }^{67}$ NINO, Carlos Santiago. Derecho, moral y política. Op. cit. p. 80.

${ }^{68}$ NINO, Carlos Santiago. Derecho, moral y política. Op. cit., p. 81 .

69 "Nos últimos anos, a tentativa mais ambiciosa e talvez mais influente de elaborar um conceito abrangente de justiça, que poderá tanto explicar a tomada de decisões judiciais quanto situá-las em bases objetivas, é aquela dos pesquisadores que atuam no campo interdisciplinar de 'direito e Economia' (Law and Economics), como se costuma chamar a Análise Econômica do direito (Economic Analysis of Law)." Cf.: POSNER, Richard A. Problemas de filosofia do direito. Tradução de Jefferson Luiz Camargo. São Paulo: Martins Fontes, 2007, p. 473.

${ }^{70}$ NINO, Carlos Santiago. Derecho, moral y política. Op. cit., p. 81-82.

\section{OS FUNDAMENTOS DA DECISÃO JUDICIAL}

O uso do precedente como fonte do direito (típico do sistema vinculante inglês - stare decisis) parece implicar que: a) não há um método único na aplicação do direito; b) não há formulação exclusiva e correta; c) os juízes passam a exercer legitimamente certa "atividade legislativa" (função criadora das regras). ${ }^{71}$ Todavia, não é assim que os fatos ocorrem. Na realidade, o stare decisis não comunga com qualquer espécie de ceticismo sobre as regras. Apesar de reconhecer que o poder discricionário dos juízes é capaz de tornar preciso um padrão inicialmente vago das regras e também de resolver problemas de incerteza das leis, Hart critica as interpretações que se apóiam nesta característica do sistema para afirmar uma certa "natureza mítica" das regras (defendendo, como conseqüência, que o direito consiste apenas na decisão dos juízes). O reconhecimento da abertura do sistema e da existência comum da área de incerteza não é compatível com uma “obsessão pela zona de penumbra", pois interpretações exageradas podem chegar a ponto de "abandonar a noção de que as regras estão dotadas de autoridade", sendo uma "fonte rica de confusão."72

$\mathrm{O}$ autor denuncia essas teses, típicas do ceticismo (ou mesmo do "realismo jurídico") como sendo componentes de um núcleo de pensamento bastante incoerente; afinal, a afirmação de que "existem decisões judiciais"

${ }^{71}$ HART, Herbert L. A. O conceito de direito. Op. cit., p. 149.

${ }^{72}$ HART, Herbert, L. A. Derecho y moral: contribuciones a su análisis. Op. cit., p. 40. 
não pode ser combinada com a "negação de que existem regras". A própria existência dos tribunais precisa decorrer de regras secundárias que estabelecem sua competência. ${ }^{73}$ Esta posição, por certo, é totalmente oposta aquela do "indeterminismo radical", propugnada pelos teóricos pragmatistas e, em particular, pelos autores ligados ao movimento Critical Legal Studies. ${ }^{74}$

Hart assevera que os céticos parecem "absolutistas desapontados". Como eles observam que as regras não são tão previsíveis como eles esperavam em seu "paraíso formal”, então acabam achando que elas não servem para nada. Isso é um equívoco. ${ }^{75}$ Por certo as regras possuem um núcleo de

${ }^{73}$ HART, Herbert L. A. O conceito de direito. Op. cit., p. 150.

${ }^{74}$ Ao menos, esta é a advertência de Juan Carlos Bayón. Cf.: BAYÓN, Juan Carlos. Por qué es derrotable el razonamiento jurídico? In: BAYÓN, Juan Carlos; RODRÍGUES, Jorge L. Relevancia normativa en la justificación de las decisiones judiciales: el debate Bayón-Rodríguez sobre la derrotabilidad de las normas jurídicas. Bogotá: Universidade Externado de Colômbia. 2003, p. 43. Jean-Cassien Billier e Aglaé Maryoli parecem concordar com a proposição afirmando que "os procedimentos de adoção e de aplicação do direito, as regras secundárias, segundo H. L. A. Hart, são percebidos como técnicas axiologicamente neutras, sem prejulgar a escolha política a fazer. Elas constituem unicamente um quadro dentro do qual acontece o debate relativo às políticas que serão perseguidas pelo legislador. Isso é errado aos olhos dos CLS, porque todo procedimento consiste em repartir entre as forças envolvidas o poder de impacto que elas podem ter sobre a decisão a tomar." Cf.: BILLIER, Jean-Cassien; MARYOLI, Aglaé. História da filosofia do direito. Op. cit., p. 459.

75 E o autor exemplifica: marcamos um compromisso; no momento agendado temos que socorrer um doente e faltamos ao compromisso agendado. $\mathrm{O}$ fato de que esta razão é aceite para que justifiquemos a ausência ao compromisso não significa que desapareça a regra de que temos que cumprir com nossos compromissos. Cf.: HART, Herbert. L. A. O conceito de direito. Op. cit., p. 153. significado estabelecido e o simples fato de que este significado possa não ser reconhecido em determinada situação concreta não implica, necessariamente, a existência de uma falha no sistema. ${ }^{76}$

É preciso reconhecer como um fato que as regras possuem uma característica especial implícita de terminarem sempre com a expressão "a menos que...". E "uma regra que termina com a expressão 'a menos que...' é ainda uma regra". ${ }^{77}$ E como decorrência deste caráter aberto, é possível extrair a conclusão de que não há uma só resposta correta a descobrir no processo de aplicação do direito. A resposta é, na realidade, "um compromisso razoável entre muitos interesses conflitantes". ${ }^{78}$

Nesse sentido, Juan Carlos Bayón esclarece que esta teoria da fundamentação (que não é exclusiva de Hart, mas de outros importantes autores como Alf Ross, ainda que em termos distintos) é uma das mais importantes contribuições da história recente para a filosofia do direito. Ou seja, superandose o positivismo clássico, passou-se a reconhecer o "caráter derrotável" do sistema. Esta nova forma de proposição passa a reforçar a idéia de que: a) o mais importante na análise da fundamentação jurídica é seu caráter "não monotônico"; ou seja, o direito

${ }^{76}$ Sobre a distinção entre derrotabilidade e falibilidade ver: BAYÓN, Juan Carlos. Por qué es derrotable el razonamiento jurídico? In: BAYÓN, Juan Carlos; RODRÍGUES, Jorge L. Relevancia normativa en la justificación de las decisiones judiciales. Op. cit., p. 284.

${ }^{77}$ HART, Herbert. L. A. O conceito de direito. Op. cit., p. 153.

${ }^{78}$ HART, Herbert L. A. O conceito de direito. Op. cit., p. 146. 
admite várias possibilidades de sua compreensão; e b) a lógica jurídica clássica é insuficiente para a análise do fenômeno jurídico. Desse modo, "afirmar que as normas jurídicas são derrotáveis - ou abertas - equivale a sustentar que estão sujeitas a exceções implícitas que não podem ser identificadas exaustivamente de antemão". ${ }^{79}$

Para os céticos, a afirmação de que um supremo tribunal estava errado é irrelevante para o sistema. A falibilidade não interessa, pois o que importa é a definitividade. Assim, “o direito (com a Constituição) é o que os tribunais dizem que é”. Hart critica esta posição e afirma: "é verdade que, para os fins do jogo, o resultado é aquilo que o marcador diz que é. Mas é importante ver que a regra de pontuação continua a ser o que era antes e é dever do marcador aplicá-la o melhor que puder." Todavia, em sendo o marcador um ser humano sua decisão é falível e "trará consigo o mesmo risco de erro não intencional de abuso ou de violação". Não parece possível ou razoável imaginar a criação de regras para a correção de violações de toda e qualquer espécie. ${ }^{80}$ Por certo a adesão do juiz à busca por uma solução pautada nas regras é uma exigência fundamental para a manutenção dos próprios padrões, mas o juiz não os cria. ${ }^{81}$

79 BAYÓN, Juan Carlos. Por qué es derrotable el razonamiento jurídico? In: BAYÓN, Juan Carlos; RODRÍGUEZ, Jorge. Relevancia normativa en la justificación de las decisiones judiciales. Op. cit., p. 293.

${ }^{80}$ HART, Herbert. L. A. O conceito de direito. Op. cit., p. 156.

${ }^{81}$ Segundo o autor, "os tribunais não consideram as regras jurídicas como predições, mas antes como padrões a seguir na decisão, suficientemente determinadas, apesar de sua textura aberta, para limitar o seu caráter discricionário, embora sem o excluir". Cf.: HART, Herbert. L. A. O conceito de direito. Op. cit., p. 161.
Nesse sentido, a advertência é particularmente válida para a teoria de Alf Ross, para quem a validade das regras jurídicas depende da forma de utilização particular delas pelos juízes. ${ }^{82}$ Como aponta Hart, "a utilização normativa das regras não se esgota na experiência psicológica à qual se refere o conceito de validade do filósofo dinamarquês". ${ }^{83}$

Fato é que leis exigem uma interpretação, sendo esta, inclusive uma característica fundante dos sistemas abertos. E os juízes são intérpretes fundamentais, devendo, no tocante à sua atividade, ser considerado que: a) não estão obrigados a uma interpretação mecânica de regras (que teriam um sentido prédeterminado apenas a ser "descoberto"); b) freqüentemente utilizam-se da razoabilidade e da finalidade como critério hermenêutico; c) consideram princípios de moral e justiça na aplicação do direito; d) promovem escolhas entre valores conflitantes. Todavia, nenhuma destas características da atividade judicial permite concluir que o juiz possui alguma espécie de função legislativa. Aliás, ao contrário do legislador, o juiz necessita objetivar algumas “virtudes essenciais", tais como: a) imparcialidade e neutralidade; b) consideração de todos os interesse envolvidos; c) embasamento da decisão em princípios aceitáveis racionalmente (levando-se em conta que sua decisão não é a única correta,

${ }^{82}$ Ross usa a terminologia "direito vigente" $\mathrm{e}$ afirma que "um ordenamento jurídico nacional, considerado como um sistema vigente de normas, pode ser definido como o conjunto de normas que efetivamente operam na mente do juiz, porque ele as sente como socialmente obrigatórias e por isso as acata". ROSS, Alf. Direito e justiça. Tradução de Edson Bini. Bauru: EDIPRO, 2003, p. 59.

${ }^{83}$ BILLIER, Jean-Cassien; MARYOLI, Aglaé. História da filosofia do direito. Op. cit., p. 266. 
"mas essa pode tornar-se aceitável com produto racional de escolha esclarecida e imparcial"). ${ }^{84}$

Nino acredita ser insuficiente entender o direito a partir da aplicação de determinadas normas pelos juízes, utilizadas por eles porque consideradas válidas em virtude de sua origem em uma autoridade legítima e legalmente competente (e esta conclusão o autor compartilha com Hart). Nino concorda, ainda, que os conceitos de validade, autoridade, legitimidade e competência são conceitos normativos. E mesmo que esse reconhecimento parta de uma convenção, a necessária tomada de posição exige um ponto de vista interno em determinado sentido. ${ }^{85}$ Aqui está o núcleo da crítica à teoria de Kelsen. Os juízes aplicam determinadas normas porque as consideram válidas. A validade decorre da elaboração da norma por legisladores legitimados e com conteúdo determinado por outras normas. A legitimidade dos legisladores decorre de uma norma de competência. A derivação de normas a partir de normas chega a um limite - a cadeia de normas de competência não pode ser infinita. A norma última não é jurídica: está fora do conceito kelseniano de direito. "O direito é identificado, segundo esse conceito, acudindo a normas não jurídicas. A motivação dos juízes se baseia, neste conceito de direito, em proposições normativas não jurídicas, posto que não são aceitas pelos juízes pelo fato de terem sido prescritas por autoridades legítimas". ${ }^{86}$

${ }^{84}$ HART, Herbert. L. A. O conceito de direito. Op. cit., p. 221.

85 NINO, Carlos Santiago. Derecho, moral y política. Op. cit., p. 56-57.

${ }^{86}$ NINO, Carlos Santiago. Derecho, moral y política. Op. cit., p. 57.
Caracterizar a primeira norma como jurídica implicaria a substituição do conceito de direito por um que incluísse todas as razões trazidas pelo juiz em uma decisão judicial. Além disso, essa norma não poderia ser válida apenas para o juiz ou ser formulada por ele, com base em interesses ou impressões puramente pessoais, ou sua decisão seria rechaçada. Essa norma, necessariamente aceita pela comunidade, está sempre submetida a uma potencial discussão. Para Nino, a adoção de normas que legitimem as fontes das normas jurídicas está submetida a uma prática discursiva que a relaciona intimamente com a moral positiva. ${ }^{87}$

Assim, uma decisão judicial reflete sobre todo o ordenamento, relaciona-se com as decisões já tomadas e com as decisões que virão, podendo ser rechaçada ou elevada a uma razão de decidir. Além disso, a atuação do juiz (como a do constituinte, do legislador e do administrador) deve contribuir para preservar e melhorar a ordem jurídica. A decisão deve incluir na sua construção e na sua motivação a consideração de seus efeitos sobre a ordem jurídica. A tomada de uma decisão moralmente justificada, para Nino, passa pela preservação da ordem jurídica a partir do momento em que se considera legítimo o ordenamento. Sob este entendimento, afastam-se as decisões incompatíveis com a preservação do direito positivo. O autor ressalta, portanto, que não há uma sobreposição da moral no direito. A valoração moral atua quando do reconhecimento da legitimidade do ordenamento jurídico e no preenchimento das indeterminações normativas. "Essas

${ }^{87}$ NINO, Carlos Santiago. Derecho, moral y política. Op. cit., p. 59. 
indeterminações permitem, na realidade, um enriquecimento e evolução da prática jurídica até formas mais aceitáveis de legitimidade sem risco de ruptura, já que são situações em que é possível buscar as soluções axiologicamente preferíveis sem enfrentar-se às inconsistências das implicações na prática". 88

O direito positivo e a aplicação do direito são ações coletivas, inspiradas por uma intenção coletiva, estendidas no tempo e inspiradas por princípios de justiça e moralidade social. Nino concorda com Ross (e Hart) ao entender que o direito deve ser obedecido pela adesão das pessoas aos seus comandos e não simplesmente por temor à sanção, o que exige que o direito se apóie em convicções morais coletivas: direito não é só coação, mas coação e autoridade e a autoridade do direito pressupõe que ele seja socialmente considerado como moralmente legítimo. ${ }^{89}$

Ao tratar da conexão entre moral e política, Nino volta ao tema do controle de constitucionalidade pelo Poder Judiciário, ponto essencial da discussão sobre o decisionismo. $\mathrm{O}$ autor afasta $\mathrm{o}$ individualismo epistêmico de Rawls por considerar que não é possível que uma pessoa sozinha, sem colocar seus argumentos à prova, chegue a uma posição de imparcialidade. Também nega o elitismo epistêmico que, sob o pretexto de afastar o direito da política (e a política do direito), permite que "juízes, juristas e filósofos assumam muitas vezes que o resultado da política democrática pode, sem

${ }^{88}$ NINO, Carlos Santiago. Derecho, moral y política. Op. cit., p. 137-143.

${ }^{89}$ NINO, Carlos Santiago. Derecho, moral y política. Op. cit., p. 144-145. mais, desqualificar-se quando um 'punhado de homens sábios' chegam à conclusão, por pura reflexão de gabinete, que dito resultado viola princípios morais, em função dos quais a Constituição é justificada e interpretada". ${ }^{90}$

Nino, assim, assume a interferência da moral sobre a decisão, mas não aceita um argumento moral individual ou coletivamente restrito. Em um Estado democrático, as soluções jurídicas mais adequadas são aquelas construídas coletivamente em uma discussão política na busca de um consenso efetivo - ou seja, na esfera política democrática. ${ }^{91}$

Relacionando (ou reconhecendo as relações entre) direito, moral e política, Nino chega à conclusão que a decisão deve porque precisa - preencher as indeterminações das preposições jurídicas, mas tomando as normas jurídicas como produto de um consenso alcançado por um processo democrático. $\mathrm{O}$ direito positivo deve ser observado, valorado, no entanto, não pela sua derivação de uma norma fundamental ou pelo reconhecimento de uma norma de competência em relação à sua fonte, mas por derivarem de uma construção coletiva democrática. $\mathrm{E}$, assim tomadas, as normas jurídicas devem ser tidas como razões substanciais para justificar ações e decisões. ${ }^{92}$

${ }^{90}$ NINO, Carlos Santiago. Derecho, moral y política. Op. cit., p. 175.

${ }^{91}$ Nino analisa a democracia como um modelo ideal de caráter processual, ligado à moral, mas imperfeito em face da substituição do consenso pela regra da maioria. Para uma análise ligada à justificação da democracia ver: RODENAS, Ángeles. Sobre la justificación de la democracia en la obra de Carlos S. Nino. Doxa: Cuadernos de Filosofía del Derecho. Universidad de Alicante. n. 10, 1991, p. 279-293.

92 NINO, Carlos Santiago. Derecho, moral y política. Op. cit., p. 188-190. 
Ao decidir, o juiz deve confiar na reflexão, discussão e decisão democráticas como capazes de determinar soluções moralmente corretas e não em sua reflexão individual. A proposta de Nino, enfim, resume-se em asseverar que o direito, entendido a partir do ponto de vista interno, está "conectado a certos princípios ideais de justiça e moralidade social, que constituem a fonte das razões justificatórias na motivação jurídica”. Todavia, não é possível olvidar que "esses princípios ideais não se aplicam diretamente às ações ou decisões jurídicas, mas se aplicam a práticas coletivas, de modo que se estas resultam justificadas por aqueles, as ações e decisões têm que ser, por um lado, compatíveis com a preservação de tais práticas e, por outro, têm que contribuir para que a prática se aproxime o mais possível de ditos princípios ideais de justiça e moralidade.” E, finalmente, é preciso considerar que tais princípios ideais não podem ser conhecidos de modo suficientemente confiável "pela mera reflexão individual isolada, senão através de processos políticos coletivos de caráter democrático. ${ }^{93}$

Deve-se registrar que, nessa seara, talvez o ponto mais polêmico e sensível de Hart esteja justamente na afirmação de um poder discricionário que é atribuível aos juízes não porque há casos difíceis (como em Dworkin), mas simplesmente porque o direito é incompleto e derrotável, ${ }^{94}$ ou seja, em um

93 NINO, Carlos Santiago. Derecho, moral y política. Op. cit., p. 193.

94 Bayón explica adequadamente esta situação: "Em definitivo, o direito se concebe como parcialmente indeterminado. $\mathrm{O}$ espaço em que resulta indeterminado seria o espaço da discricionariedade do intérprete, no qual a solução dos casos, por definição, não pode fazerse derivar do direito e no qual por isso mesmo não é indeterminado número de casos admite exceções implícitas às regras e, em certas questões, mais do que isso, realmente não oferece qualquer resposta. Afinal, as situações de fato não estão de pronto definidas e escritas para que os juízes simplesmente as leiam. "Ao contrário, ao aplicar as regras jurídicas alguém deve assumir a responsabilidade de decidir que as palavras se referem ou não a certo caso, com todas as conseqüências práticas que esta decisão implica". ${ }^{95}$

O próprio Hart observa que Dworkin rejeita a incompletude e a responsabilização discricionária, pois o que seria admissível é apenas uma controvérsia razoável que às vezes não permite demonstração conclusiva se a inferência é falsa ou verdadeira. ${ }^{96}$ Assim, torna-se possível identificar uma interessante dicotomia entre a posição de Hart (do "direito incompleto") e de Dworkin (do "direito controvertido"). Em termos mais específicos, Hart afirma que o dever fundamental do juiz é ter o "melhor juízo moral que puder sobre quaisquer questões morais que possa ter para decidir". ${ }^{97}$ Dessa forma, o autor parece reconhecer que há uma esfera subjetiva na decisão do juiz (a partir de suas próprias

possível ser oposta barreira alguma à irrupção do discurso moral geral." Cf.: BAYÓN, Juan Carlos. Proposiciones normativas e indeterminación del derecho. In: BAYÓN, Juan Carlos; RODRÍGUEZ, Jorge. Relevancia normativa en la justificación de las decisiones judiciales. Op. cit., p. 42.

${ }^{95}$ HART, Herbert. L. A. Derecho y moral: contribuciones a su análisis. Op. cit., p. 26.

${ }^{96}$ HART, Herbert. L. A. O conceito de direito. Op. cit., p. 314 .

${ }^{97}$ HART, Herbert. L. A. O conceito de direito. Op. cit., p. 316. 
convicções), que depende de sua précompreensão e não pode ser verificada pelo direito. Nesse sentido, portanto, contrapondose fortemente a Dworkin, que defende a presença de uma "moral de caráter objetivo" na decisão judicial. ${ }^{98} \mathrm{Ou}$, ainda, como prefere Vera Karam de Chueiri, "a concepção do direito como integridade se estrutura sobre uma conexão racional (hermenêutico-crítica) entre o direito e a moral." Desse modo, segundo a autora, a teoria de Dworkin acaba oferecendo um distinto ponto de partida interpretativo do direito ao propiciar uma "nova feição ao debate secular entre direito e moral, entre ser e dever ser, a superar a dicotomia positivista, bem como a confusão do direito natural". 99

Percorrendo caminho semelhante, por sua vez, Nino sustenta que a interpretação transforma o material jurídico em proposições que podem ser empregadas na motivação prática. A interpretação inicia-se com o preenchimento dos materiais jurídicos expressos pela linguagem, sempre complexa e freqüentemente controvertida - de um sentido geral. Isso pode dar-se em um sentido subjetivista (que busca a intenção do autor do texto) ou objetivista (que considera o uso comum dos termos). Neste preenchimento

98 Segundo Dworkin, deve ser respeitado o requisito da “integridade constitucional”. Ou seja, não devem os juízes dedicir conforme suas convicções particulares. Eles devem associar-se a um todo constitucional. E sua decisão deverá ser legitimada mediante uma fundamentação que parta desta premissa. Cf.: DWORKIN, Ronald. La lectura moral y la premisa mayoritarista. In: KOH, Harold Hongju e SLYE, Ronald (Comp.). Democracia deliberativa y derechos humanos. Op. cit., p. 110.

${ }^{99}$ CHUEIRI, Vera Karam de. Filosofia do direito e Modernidade: Dworkin e a possibilidade de um discurso instituinte de direitos. Curitiba: JM, 1995, p. 108. de sentido ressaltam as convenções sociais lingüísticas, que limitam, inclusive, a referência às intenções do autor do texto legislativo. O sentido subjetivista encontra um sério obstáculo quando a construção do texto normativo se dá por um órgão plural, colegiado. A busca de atas de discussões e sessões legislativas na tentativa de encontrar uma intenção comum que possa servir para elucidar o significado do texto, para Nino, "implica uma completa idealização, resultado também de uma série de valorações". ${ }^{100}$ A valoração, portanto, sempre estará presente no preenchimento do sentido geral dos materiais jurídicos.

A resistência de Hart em sua vinculação positivista parece decorrer, num primeiro momento, da tentativa de afastar qualquer versão psicologizante (tal como em Ross), afirmando que é necessário ao juiz se apoiar nos "conteúdos de um texto jurídico, nas técnicas de interpretação aceitas, nos trabalhos preparatórios, nos precedentes, nos princípios jurídicos (padrões)". ${ }^{101}$ Mas, mesmo assim, segundo concluem Jean-Cassien Billier e Aglaé Maryoli, na sua concepção (e assim também pensava Kelsen), o juiz decide de forma subjetiva, pois também acaba sendo fonte do direito, decidindo a partir de princípios extrajurídicos, imperativos materiais e "boas razões". Neste campo haveria, portanto, uma "ação decisionista" do juiz (que age na prática como um legislador, embora sem legitimidade). ${ }^{102}$

${ }^{100}$ NINO, Carlos Santiago. Derecho, moral y política. Op. cit., p. 91.

${ }^{101}$ BILLIER, Jean-Cassien; MARYOLI, Aglaé. História da filosofia do direito. Op. cit., p. 268.

${ }^{102}$ BILLIER, Jean-Cassien; MARYOLI, Aglaé. História da filosofia do direito. Op. cit., p. 405. 
Por esse motivo, torna-se importante a teorização de Nino, para quem, na construção da decisão judicial há uma relação intrínseca entre o direito e a moral que, todavia, não justifica, a priori, qualquer decisionismo. Internamente, portanto, há sempre uma remissão a uma justificativa que não está inserida nas normas jurídicas: uma norma moral - partilhada coletivamente e submetida à discussão - para além das normas de competência. Contudo, em Estados democráticos, o "processo democrático" é a única fonte de legitimidade da autoridade da ordem jurídica. ${ }^{103} \mathrm{O}$ papel do Poder Judiciário em um Estado democrático, portanto, e a extensão do controle de constitucionalidade é uma discussão que extrapola o campo jurídico e inclui razões axiológicas sobre o fundamento da democracia e o conteúdo dos direitos fundamentais. ${ }^{104}$

Segundo Nino, "a eventual faculdade dos juízes de desqualificar uma norma jurídica de origem democrática por violar uma prescrição constitucional, seja em relação ao procedimento ou ao conteúdo da norma, é uma arma poderosa nas mãos de órgãos que não são o resultado direto de consensos democráticos nem estão submetidos a responsabilidade democrática direta". Fugindo da condescendência de Hart e Ross com a subjetividade judicial potencialmente antidemocrática, e alinhando-se, nesta advertência, a Carl Schmitt, ${ }^{105}$ Leon Duguit

${ }^{103}$ NINO, Carlos Santiago. Derecho, moral y política. Op. cit., p. 66-67.

${ }^{104}$ NINO, Carlos Santiago. Derecho, moral y política. Op. cit., p. 71.

${ }^{105}$ Para Schmitt, a eleição do Poder Judiciário como guardião da Constituição decorre de "uma idéia mal e Gaston Jezè ${ }^{106}$ (e até mesmo como o próprio Kelsen admite), ${ }^{107} \mathrm{o}$ autor reconhece que os juízes muitas vezes podem "reorientar toda a prática constitucional" desconsiderando totalmente um consenso democrático contrário. Algo que, no mínimo, deve ser colocado em discussão. ${ }^{108}$

compreendida ou abstrata do Estado de direito" e que leva a uma politização da justiça que dissimula uma decisão política sob o manto da neutralidade e da imparcialidade. SCHMITT, Carl. O guardião da Constituição. Tradução de Geraldo de Carvalho. Belo Horizonte: Del Rey, 2007, p. 33 e seguintes.

${ }^{106}$ Em debate com Kelsen no Instituto Internacional de direito Político em outubro de 1928, Duguit aceita apenas o afastamento de uma norma considerada inconstitucional pelo juiz em um caso concreto, mas afirma que a declaração de nulidade de uma norma por uma jurisdição constitucional especial seria criar uma terceira ou primeira assembléia política. Jezè, na mesma ocasião, defende o controle político de constitucionalidade no âmbito do Poder Legislativo, "porque é necessário desconfiar do espírito conservador dos juízes e mesmo dos juristas, que por natureza são tradicionalistas e propensos a imobilizar a interpretação dos textos: é perigoso confiar a eles a missão de dizer o direito em matéria política". KELSEN, Hans. Jurisdição constitucional. Tradução do alemão Alexandre Krug, tradução do italiano Eduardo Brandão, tradução do francês Maria Ermantina Galvão, revisão técnica Sérgio Sérvulo da Cunha. São Paulo: Martins Fontes, 2003. p. 192 e 194.

${ }^{107}$ Kelsen considera extremamente perigosa a atuação do Poder Judiciário quando enfrenta termos abertos em preceitos constitucionais, pois permite que concepções como justiça, liberdade, igualdade e moralidade sejam preenchidas com qualquer significado e revestem a jurisdição constitucional com uma força "simplesmente insuportável", pois permitiria que se opusesse à maioria da população com um evidente deslocamento do poder político. KELSEN, Hans. Jurisdição constitucional. Op. cit., p. 167-169.

${ }^{108}$ NINO, Carlos Santiago. Derecho, moral y política. Op. cit. p. 68 . 


\section{REFERÊNCIAS}

ALEXY, Robert. La fundamentación de los derechos humanos en Carlos S. Nino. Doxa: Cuadernos de Filosofía del Derecho.

Universidad de Alicante. n. 26, 2003.

BAYÓN, Juan Carlos; RODRÍGUES, Jorge L. Relevancia normativa en la justificación de las decisiones judiciales: el debate Bayón-

Rodríguez sobre la derrotabilidad de las normas jurídicas. Bogotá: Universidade Externado de Colômbia, 2003.

BILLIER, Jean-Cassier; MARYOLI, Aglaé. História da Filosofia do direito. Tradução de Maurício de Andrade. Barueri-SP: Manole, 2005.

CHUEIRI, Vera Karam de. Filosofia do direito e Modernidade: Dworkin e a possibilidade de um discurso instituinte de direitos. Curitiba: JM, 1995.

DWORKIN, Ronald. La lectura moral y la premisa mayoritatista. In: $\mathrm{KOH}$, Harold Hongju e SLYE, Ronald (Comp.). Democracia deliberativa y derechos humanos. Barcelona: Gedisa, 2004.

DWORKIN, Ronald. Levando os direitos a sério. Tradução de Nelson Boeira. São Paulo: Martins Fontes, 2002.

DWORKIN, Ronald. $O$ império do direito. Tradução de Jefferson Luiz Camargo. São Paulo: Martins Fontes, 1999.

GUIBOURG, Ricardo A. Hart, Bulygin y Ruiz, Manero: tres enfoques para un modelo. Doxa:

Cuadernos de Filosofia del derecho, n. 14, 1993.

HART, Herbert L. A. O conceito de direito.

Tradução de A. Ribeiro Mendes. 4. ed., Lisboa: Fundação Calouste Gulbenkian, 2005.

HART, Herbert. L. A. Derecho y moral: contribuciones a su análisis. Tradución de Genaro Carrió. Buenos Aires: Depalma, 1962.

KELSEN, Hans. Jurisdição constitucional. Tradução do alemão Alexandre Krug, tradução do italiano Eduardo Brandão, tradução do francês Maria Ermantina Galvão, revisão técnica Sérgio Sérvulo da Cunha. São Paulo: Martins Fontes, 2003.
KELSEN, Hans. Teoria Geral do direito e do Estado. Tradução de Luís Carlos Borges. São Paulo: Martins Fontes, 2000.

MALEM, Jorge. De la imposición de la moral por el derecho: la disputa Devlin-Hart. Revista Isonomía. N. 04 (1996).

NINO, Carlos Santiago. Derecho, moral y política. Una revisión de la teoría general del Derecho. Barcelona: Ariel, 1994.

NINO, Carlos Santiago. Introducción al análisis del derecho. Buenos Aires: Editorial Astrea de Alfredo y Ricardo Depalma, 1998.

PARANO, Juan Ramón de. Entrevista de H. L. A. Hart. Doxa: Cuadernos de filosofia del derecho, n. 5 (1988), p. 340.

POSNER, Richard A. Problemas de filosofia do direito. Tradução de Jefferson Luiz Camargo. São Paulo: Martins Fontes, 2007.

ROBLES, Gregório. Hart: algunos puntos críticos. Actas del XVIII Congreso mundial de la Asociación Internacional de Filosofia Jurídica y social. Buenos Aires, 1977.

RODENAS, Ángeles. Sobre la justificación de la democracia en la obra de Carlos S. Nino. Doxa: Cuadernos de Filosofía del Derecho. Universidad de Alicante. n. 10, 1991.

ROSS, Alf. Direito e justiça. Tradução de Edson Bini. Bauru: EDIPRO, 2003.

SCHMITT, Carl. O guardião da Constituição. Tradução de Geraldo de Carvalho. Belo Horizonte: Del Rey, 2007.

SILVA, Artur Stamford et alli. Construção judicial do direito. Desde Kelsen e Hart. Ainda somos os mesmos... e vivemos. Revista de Informação Legislativa, Brasília, n. 165, p. 205-218, jan/mar 2005. 